\title{
A DOFS-Based Approach to Calculate the Height of Water- Flowing Fractured Zone in Overlying Strata under Mining
}

\author{
Chunde Piao $\mathbb{D}^{1,2}$ Jinjun Li, ${ }^{3}$ Dangliang Wang, ${ }^{1}$ and Wei Qiao $\mathbb{D}^{1}$ \\ ${ }^{1}$ School of Resources and Geosciences, China University of Mining and Technology, Xuzhou 221116, China \\ ${ }^{2}$ State Key Laboratory for Geomechanics and Deep Underground Engineering, China University of Mining and Technology, \\ Xuzhou 221116, China \\ ${ }^{3}$ Shenhua Geological \& Exploration Company Ltd., China Energy Group, Beijing 102211, China
}

Correspondence should be addressed to Chunde Piao; piaocd@cumt.edu.cn

Received 20 August 2020; Revised 18 September 2020; Accepted 5 March 2021; Published 17 March 2021

Academic Editor: Yingfang Zhou

Copyright (c) 2021 Chunde Piao et al. This is an open access article distributed under the Creative Commons Attribution License, which permits unrestricted use, distribution, and reproduction in any medium, provided the original work is properly cited.

\begin{abstract}
The distributed optical fiber sensing (DOFS) is a technique that can obtain full spatial and temporal information concerning the behavior of a large range of measurand fields along a fiber path and realize the distributed monitoring of the overburden section under mining. To calculate the height of water-flowing fractured zone caused by the exploitation of coal, this study employed distributed optical fiber sensors with OSI-C-S optical frequency domain reflectometry (OFDR) technology and designed a similar-material model test based on the engineering geological conditions of Daliuta Coal Mine. Through the test, deformation characteristics of overlying strata were studied, the linear relationship was summarized between the strain gradient and the shear stress measured by fiber sensors when the rock layer cracks, and a method was proposed of using the measured strain to measure the height of the water-flowing fractured zone in overlying strata. The test results show that there are several locations where the sign of the shear stress changes (positive to negative or vice versa) in the overlying strata during the initial stage of coal seam mining. As the working face advanced, the change locations gradually concentrated at the place where the rock cracks. By identifying the breakpoints of the rock and the locations where the sign of the shear stress measured by fiber sensors changes, this paper calculated the height of the water-flowing fractured zone in Daliuta Coal Mine. After comparing the height with the abscission layer position in the model test and the predicted height by the empirical formulas in the specification, it has been found that the three results are basically consistent, which in turn verifies the accuracy of this method.
\end{abstract}

\section{Introduction}

After the coal seam is mined, the overlying strata gradually move to the gob. According to the severity of deformation and failure of the rock mass, the overlying strata in the gob can be divided into three zones: caving zone, fracture zone, and bending zone. The caving zone and fracture zone are collectively called the water-flowing fractured zone [1]. The water-flowing fractured zone caused by the exploitation of coal can form a channel for water inrush in the mine and pose a threat to the safety of coal mining under a body of water. As the height of the water-flowing fractured zone is a key parameter, therefore accurate calculation of its height is very important for safe mining as well as environment conservation [2]. According to the mining thickness of coal seam and the properties and distribution characteristics of overlying strata, many theoretical formulas for calculating the height of water-flowing fractured zones have been proposed [3-5]. However, because coal mines are widely distributed in China, and geological conditions, overburden structures, and mining techniques in different areas vary greatly, the existing proposed formulas are affected by regional parameters, hypothetical conditions, and applicability, therefore cannot be used universally. For example, for the numerical simulation method, it is difficult to select the rock mass parameters involved, the model is difficult to accurately match the actual project, and it needs to be verified with actual monitoring data [6]. The monitoring of rock mass deformation is an important means to master the deformation rules of overlying strata. Common field-testing 
techniques for measuring the overburden deformation include loss observation of flush fluid, electromagnetic method, and borehole TV system. These testing techniques have their own advantages and disadvantages depending on the geological conditions and mining conditions. The loss observation of flush fluid is simple, but the test accuracy is greatly affected by human factors and the test time is relatively longer [7]. The electromagnetic method is affected by factors such as formation properties, structural distribution, and image interpretation and is mainly used to assist detection [8]. The borehole TV system can observe the geological conditions in the borehole by using photos or video images. The test method is simple, but the detection accuracy is undermined when the borehole contains water or the hole collapses $[7,9]$.

The distributed optical fiber sensing (DOFS) technology has many advantages such as distributed monitoring, long distance monitoring, good durability, strong anti-interference, and good performance of coordinating with the measured object. Though DOFS has been widely used in geotechnical engineering [10-12], the application research of this technology in the coal mining field is still in the exploration stage due to such features as the large depth of coal seams, complex multifield effects of rock and soil, and the sever deformation of mined overburden. In recent years, by analyzing the abnormal characteristics of measured values and the surge loss point of the optical fiber cable [13], the peak of the Brillouin frequency shift [14], and the layer of the fiber cable breakpoint [15], many research achievements have been made in measuring the height of the water-flowing fractured zone. But no specific criteria have been established. Through making a similar-material test model and using optical frequency domain reflectometry (OFDR) technology, this study analyzed the deformation and failure characteristics of overburden under mining conditions, studied the strain distribution rules, explored the strain changes and shear stress sign changes when the rock cracks, and proposed a method of using the measured strain to measure the height of the water-induced fractured zone in overlying strata. This paper has provided theoretical basis and technical support for the identification of rock cracks and safe mining of coal mines.

\section{Theoretical Method to Measure the Height of the Water-Flowing Fractured Zone}

2.1. OFDR Test Principle. Optical frequency domain reflectometry technology (OFDR) is a strain measurement technology based on variations of Rayleigh scattered light. It uses continuous wave frequency scanning technology to establish the linear dependence of frequency drifts of Rayleigh back-scattered light spectrum with the strain and temperature along the length of an optical fiber, thus realizing the distributed measurement of the measured structure and obtaining a high spatial resolution $[16,17]$.

When using OFDR to measure the tested structure, temperature changes affect the strain value. Therefore, the strain test of optical fiber was performed indoors under different

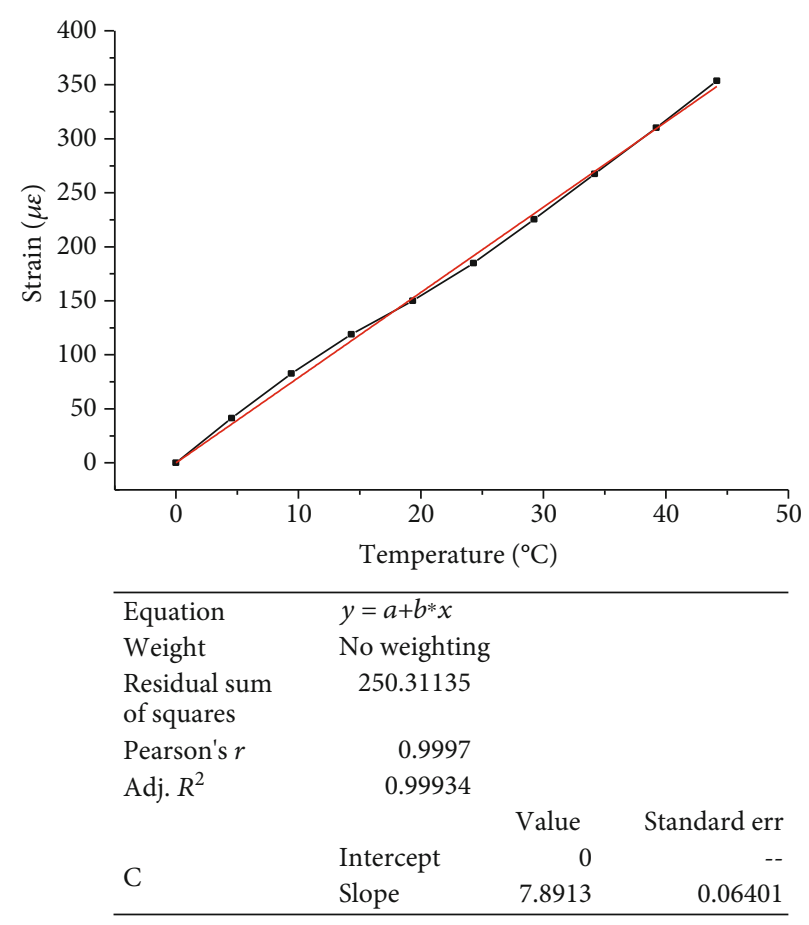

FIGURE 1: Linear relationship between strain and temperature (obtained by OFDR measurements).

temperature conditions. The test results are shown in Figure 1.

It can be seen from Figure 1 that when the structure was measured by using the OFDR, a strong linear relationship existed between the change in strain and temperature with the slope of $7.8913 \mu \varepsilon /{ }^{\circ} \mathrm{C}$. That is, for each change of $1^{\circ} \mathrm{C}$ in temperature, the measured strain will change accordingly by $7.8913 \mu \varepsilon$. According to the laboratory tests, a change of less than $10^{\circ} \mathrm{C}$ in rock mass temperature caused by aquifer leakage would result in a variation of $80 \mu \varepsilon$ in strain [18], which was far smaller than the strain (greater than $600 \mu \varepsilon$ ) generated during rock damage. Therefore, the temperature change induced by aquifer leakage when the cracks appeared in the rock layer had few impacts on the measured strain and could not affect the strain-based identification of open fractures.

2.2. Measure the Height of Water-Flowing Fractured Zone by Analyzing Strain Measured through Vertical Boreholes. In order to grasp the characteristics of deformation and failure of overlying strata under mining conditions, an optical fiber sensor was laid from the ground to the coal mining area. Figure 2 shows the distributed monitoring and deformation characteristics of overlying strata under coal mining.

There are two steps to determine the height of the waterflowing fracture zone based on the DOFS technology.

2.2.1. Rock Breakpoint Identification. It can be seen from Figure 2 that the coal seam mining caused the rock strata to move and deform towards the direction of the gob (worked-out area at the bottom) and two zones (water-flowing fractured zone and bending zone) were gradually 


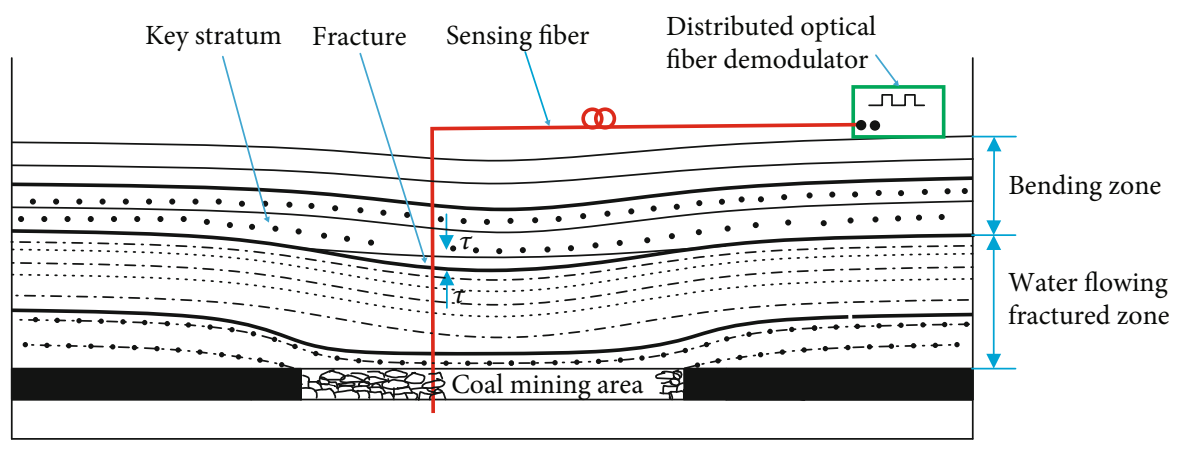

FIGURE 2: Distributed monitoring and deformation characteristics of overlying strata under coal mining.

generated in the overlying strata. The tensile strength of the rock was far weaker than its compressive strength. Most of the deformation was tensile deformation. When the stress of the rock caused by the mining of the coal seam is greater than its tensile strength, the rock will be damaged [13]. The identification of the breakpoint at this time can be calculated by formula (1).

$$
[\sigma] \geq \sigma_{t} .
$$

In the formula, $[\sigma]$ is the stress on the rock caused by coal seam mining, which is calculated by the formula $[\sigma]=E_{\text {rock }} \cdot \varepsilon$ . Here, $E_{\text {rock }}$ is the elastic modulus of the rock and $\varepsilon$ is the strain on the rock. Before tension cracks appeared within the rock, the fiber sensor deformed along with the surrounding rock. Therefore, the strain monitored by the fiber sensor is considered as the degree of rock deformation. $\sigma_{t}$ is the tensile strength of the rock.

2.2.2. Identification of Overburden Fracture Position. With the advance of the working face, the immediate roof and the basic roof were successively damaged, fractures and abscission layer occurred due to settlement differences between the main key stratum, inferior key stratum of the overlying rock layer or the hard rock, and the lower rock mass. When a fracture occurred in a key stratum or hard rock, the key stratum or the upper rock layer was settled, and the lower rock layer was further compressed.

In Figure 2, when fractures occurred in the rock, the upper and lower rock layers were relatively far away from each other, but shear deformation occurred between the fiber sensor and the rock. At this point, the direction of the shear stress on the fiber sensor at the lower part of the fractured rock was deviating from the mining area, while the direction of the shear stress on the fiber sensor at the upper part of the fractured rock was pointing to the mining area. The shear stress on the rock mass can be calculated by formula (2) [19].

$$
\tau=\frac{E_{\mathrm{fiber}} \cdot D}{4} \cdot \frac{\mathrm{d} \varepsilon}{\mathrm{dx}}
$$

In the formula, $\tau$ is the shear stress acting on the sensing optical fiber. The shear stress pointing to the mining area takes a negative value, and the shear stress deviating from the mining area takes a positive value.
$E_{\text {fiber }}$ is the elastic modulus of the fiber sensor; $D$ is the diameter of the fiber sensor; $\mathrm{d} \varepsilon / d x$ is the strain gradient of fiber sensor along the vertical direction of overlying strata.

According to formula (2), the shear stress between the fiber sensor and the surrounding rock and soil mass is proportional to the strain gradient. The changes of the strain gradient directly reflect the magnitude of shear stress.

The overburden deformation started from the roof of the coal seam and gradually extended from the bottom to the top. By using formula (1) to identify rock breakpoints and using formula (2) to calculate the highest location where the shear stress changed from a positive value to a negative one, the study pinned down the height of the water-flowing fractured zone at the current mining stage.

\section{Similar-Material Model Test of Coal Mining}

3.1. Test Model Design. As one of the seven largest coal fields in the world, Shendong Coalfield is the largest coalfield with proven reserves in China. Daliuta Coal Mine in the Shendong Coalfield is located in the northernmost part of Shenmu county, $57 \mathrm{~km}$ away from the center of the county. By referring to the drilling data of J60 in Daliuta Coal Mine and using the working face of 2-2 coal seam as the background, the study made a test model with the length, height, and width at $300 \mathrm{~cm}, 105.9 \mathrm{~cm}$, and $30 \mathrm{~cm}$, respectively, based on the similarity theory.

According to field conditions of Daliuta Coal Mine, the following similarity parameters are selected: geometrical similarity ratio (taken as $C_{l}=100$ ), time similarity ratio $\left(C_{t}=\sqrt{C_{l}}=10\right)$, bulk density similarity ratio $\left(C_{\gamma}=\gamma_{M} / \gamma_{H}=1.5\right), \quad$ and stress similarity ratio $\left(C_{R}=R_{M} / R_{H}=C_{l} \cdot \gamma_{M} / \gamma_{H}=150\right)$. In the formula $C_{R}=R_{M} /$ $R_{H}=C_{l} \cdot \gamma_{M} / \gamma_{H}, R_{M}$ and $R_{H}$ are the mechanical strength of the prototype and the model, respectively, and $\gamma_{M}$ and $\gamma_{H}$ are the bulk density of the prototype and the model, respectively. The mechanical parameters of the prototype and test model of Daliuta Coal Mine and the ratio of similar materials are shown in Table 1 [20].

The inclination angle of the strata in Daliuta Coal Mine is near horizontal. For the ease of laying, the model was treated as horizontal rock formations. Each rock stratum in the test model was developed based on the ratio for similar physical properties in Table 1. River sand was used as aggregate, 


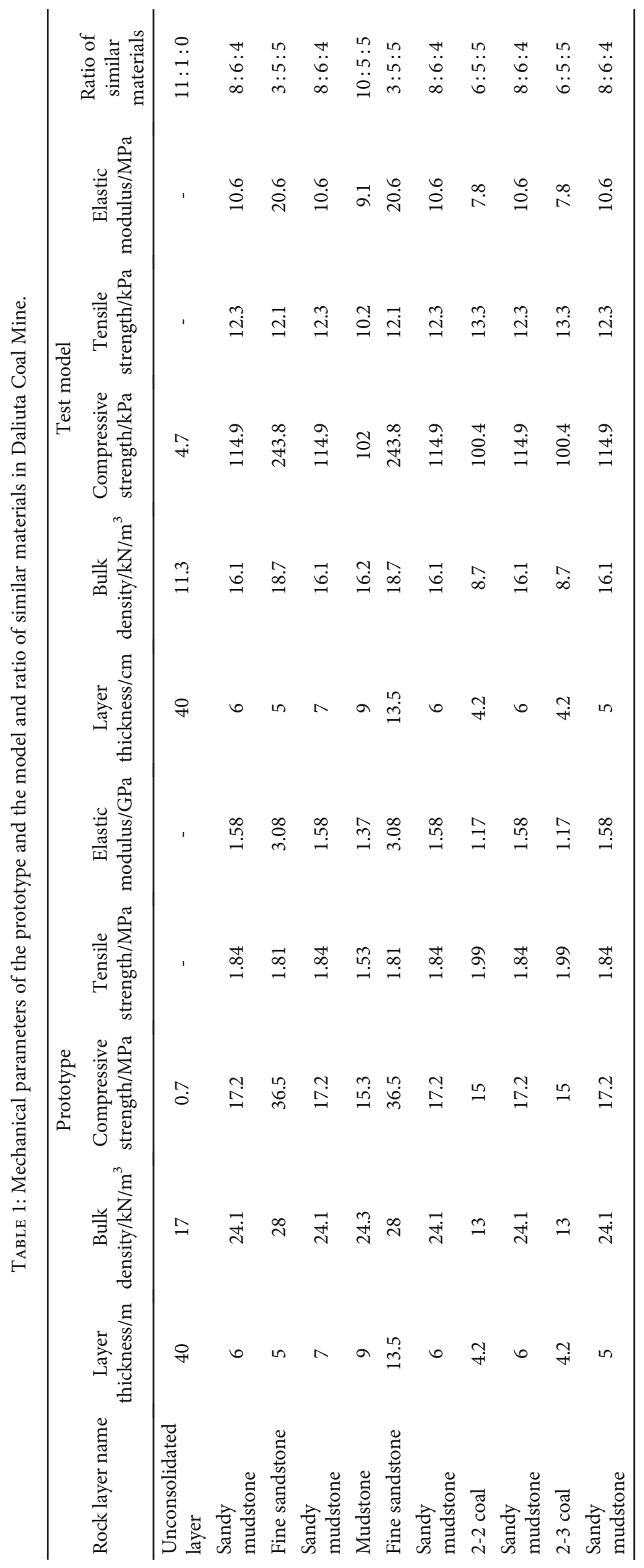


calcium carbonate and gypsum were used as cement raw materials, and borax was used as retarder. After various materials were mixed evenly, the materials with similar physical properties were generated. In order to ensure the strength of the laying model, the generated materials were hammered and compacted layer by layer from the bottom to the top in the model test bed. The thickness of each layer of coal rock stratum was no more than $3 \mathrm{~cm}$, and the surface of each layer was coated with coarse mica powder to separate the layers. The river sand used in the model was dried and screened to remove large particles and ensure particle uniformity and stability of test data. In the model test, wood strips with a length of $5 \mathrm{~cm}$ and a height of $4.2 \mathrm{~cm}$ were closely arranged to simulate coal seams to facilitate coal mining and ensure the same advance distance. According to the geometric similarity ratio, the actual advance distance and mining height simulated in this model test are $5 \mathrm{~m}$ and $4.2 \mathrm{~m}$, respectively.

3.2. Overlying Stratum Monitoring Scheme for Coal Seam Mining. The test used OSI-C-S OFDR to measure the distribution of overburden strain during coal seam mining. Test equipment is shown in Figure 3.

Table 2 shows the test parameters of the OSI-C-S OFDR test equipment.

The test used the polyurethane sheath fiber sensor with a diameter of $2 \mathrm{~mm}$ to test the overburden strain. Figure 4 shows a physical view and a cross-sectional view of the polyurethane sheath fiber sensor.

The mechanical properties and sensing properties of the polyurethane sheath fiber sensor are shown in Table 3.

The outer layer of the polyurethane sheath fiber sensor is made of a smooth soft adhesive material. During the mining process, the monitoring positions may be staggered, affecting the accuracy of the measured data. Therefore, the fiber sensor in the test section was coated with colloid and sand and was dried to increase the roughness of the surface and to improve the coupling between the fiber sensor and the model rock mass. Figure 5 shows the pretreatment of the fiber sensor.

Figure 6 shows the similarity model made by similar materials of rock stratum in Daliuta Coal Mine in Table 1.

As can be seen from Figure 6, in order to ensure that the mining boundary does not affect the deformation of overlying strata of the coal seam, the open-off cut of 2-2 coal seam in the test was located at $75 \mathrm{~cm}$ from the left of the model, with the advance distance of the model being $125 \mathrm{~cm}$ and the advance distance of the simulated working face being $125 \mathrm{~m}$. In order to detect the characteristics of overburden deformation of coal seam, line $\mathrm{B}$ and line $\mathrm{C}$ fiber sensors were embedded in the mining area of coal seam, and line A and line D fiber sensors were embedded in the pillar area of coal seam. The distances between lines A, B, C, and D and the left boundary of the model were $50 \mathrm{~cm}, 115 \mathrm{~cm}, 190 \mathrm{~cm}$, and $250 \mathrm{~cm}$, respectively. Considering the high-intensity mining of overlying strata in the coal seam, a section which was $115 \mathrm{~cm}$ to $170 \mathrm{~cm}$ away from the left boundary was selected as the study area, to test the method for measuring the height of the water-flowing fractured zone in the process of coal seam mining.

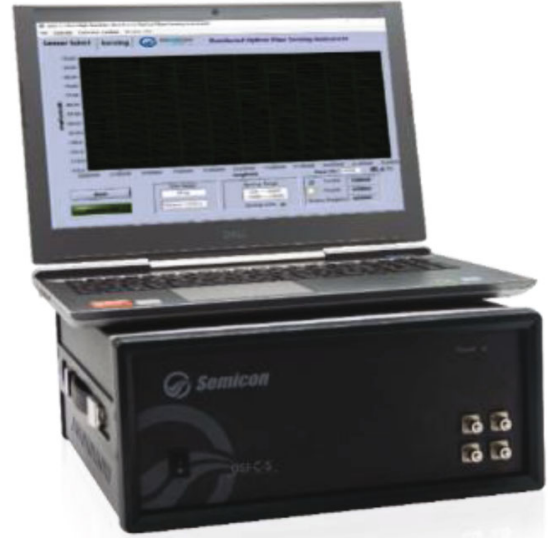

FIgURE 3: OSI-C-S OFDR test equipment.

Before the coal seam mining test, all fiber sensors were connected to the test instrument independently and the initial strain of overburden was tested. Each time when the working face advanced by $5 \mathrm{~cm}$, the test model was left to stand still for 30 minutes. The data collection of each mining stage started only after the overburden deformation was stabilized during 30 minutes. This data collection procedure was adopted until the end of the test. The actual overburden strain equals to the overburden strain caused by coal seam mining minus the initial strain.

\section{Test Result Analysis}

After the working face passed the monitoring point of line B, the roof of the coal seam was taken as the starting reference point, and the deformation range from the starting reference point up to the ground was defined as the affected depth. The overburden strain distribution caused by each mining of the coal seam is shown in Figure 7.

As can be seen from Figure 7, the working face passed the monitoring section of line $\mathrm{B}$ fiber sensor. As the working face advanced by $5 \mathrm{~cm}$, the strain value at the distance of $5 \mathrm{~cm}$ away from 2-2 coal seam roof was $1433 \mu \varepsilon$. After comparing the strain value with the tensile strength of the rocks in Table 1 and combining the calculation of formula (1), it can be indicated that at this time, the rock layer $5 \mathrm{~cm}$ away from the roof has been damaged and the upper rock mass was in a stable state. With the advance of the working face, the strain value decreased gradually due to the stress release of the rock mass in the original disturbance area, but the strain between the key stratum of fine sandstone (9) and sandy mudstone (8) increased gradually. As the working face advanced to $40 \mathrm{~cm}$, the strain gradually concentrated at $14.3 \mathrm{~cm}$ and $37.8 \mathrm{~cm}$ away from the roof of the coal seam, and its magnitude was $662 \mu \varepsilon$ and $1836 \mu \varepsilon$, respectively. After comparing the strain value with the tensile strength of the rocks in Table 1 and combining the calculation of formula (1), it can be indicated that the rock strata broke at this time. As the working face advanced to $55 \mathrm{~cm}$, the strain value surged at the place $37.8 \mathrm{~cm}$ away from the roof of the coal seam, reaching $6065 \mu \varepsilon$, after which the test signal weakened and the strain value could not be measured accurately. 
TABLE 2: Test parameters of the OSI-C-S OFDR instrument.

\begin{tabular}{cccccccc}
\hline Name & Test length & $\begin{array}{c}\text { Number of test } \\
\text { channels }\end{array}$ & $\begin{array}{c}\text { Spatial } \\
\text { resolution }\end{array}$ & Sampling rate & $\begin{array}{c}\text { Strain test } \\
\text { range }\end{array}$ & $\begin{array}{c}\text { Strain test } \\
\text { accuracy }\end{array}$ & $\begin{array}{c}\text { Temperature } \\
\text { range }\end{array}$ \\
\hline Option & $\begin{array}{c}\text { Up to } \\
100 \mathrm{~m}\end{array}$ & 4 & $1 \mathrm{~mm}$ or $1 \mathrm{~cm}$ & $\begin{array}{c}4 \mathrm{hz} \text { as the } \\
\text { fastest }\end{array}$ & $\pm 12000 \mu \varepsilon$ & $\pm 1.0 \mu \varepsilon$ & $-200^{\circ} \mathrm{C} \sim 1200^{\circ} \mathrm{C}$ \\
\hline
\end{tabular}

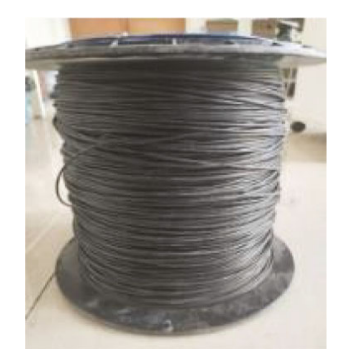

(a) Physical map

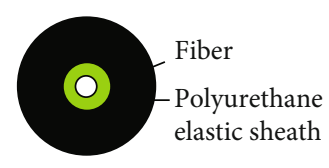

(b) Profile

FIgure 4: Polyurethane sheath fiber sensor.

TABLE 3: Mechanical properties and sensing performance of polyurethane sheath fiber sensor.

\begin{tabular}{lccccccc}
\hline $\begin{array}{l}\text { Parameter } \\
\text { category }\end{array}$ & $\begin{array}{c}\text { Fiber } \\
\text { diameter/mm }\end{array}$ & $\begin{array}{c}\text { Core } \\
\text { diameter/mm }\end{array}$ & $\begin{array}{c}\text { Maximum } \\
\text { breaking force/N }\end{array}$ & $\begin{array}{c}\text { Modulus of } \\
\text { elasticity/GPa }\end{array}$ & $\begin{array}{c}\text { Coefficient of } \\
\text { strain/MHz/ } \mu \varepsilon\end{array}$ & $\begin{array}{c}\text { Temperature } \\
\text { coefficient/MHz } /{ }^{\circ} \mathrm{C}\end{array}$ & $\begin{array}{c}\text { Strain } \\
\text { measuring } \\
\text { range/ } \mu \varepsilon\end{array}$ \\
\hline Value & 2.0 & 0.9 & 220 & 0.2 & 0.04998 & 1.89 & $-10000 \sim 20000$ \\
\hline
\end{tabular}

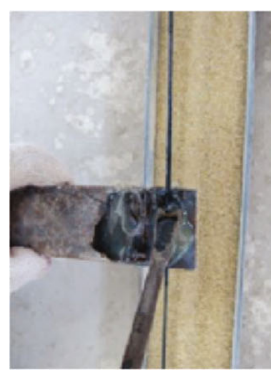

(1) glue applying

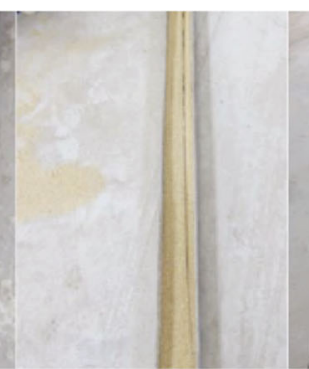

(2) sand sticking

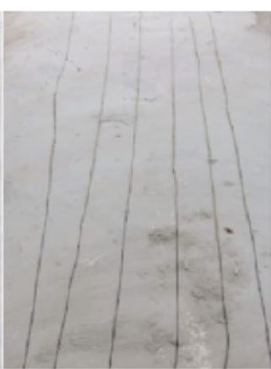

(3) drying

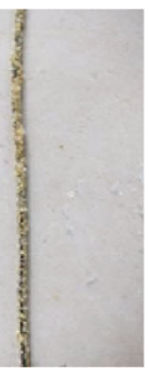

(4) finished product

Figure 5: Pretreatment of fiber sensor.

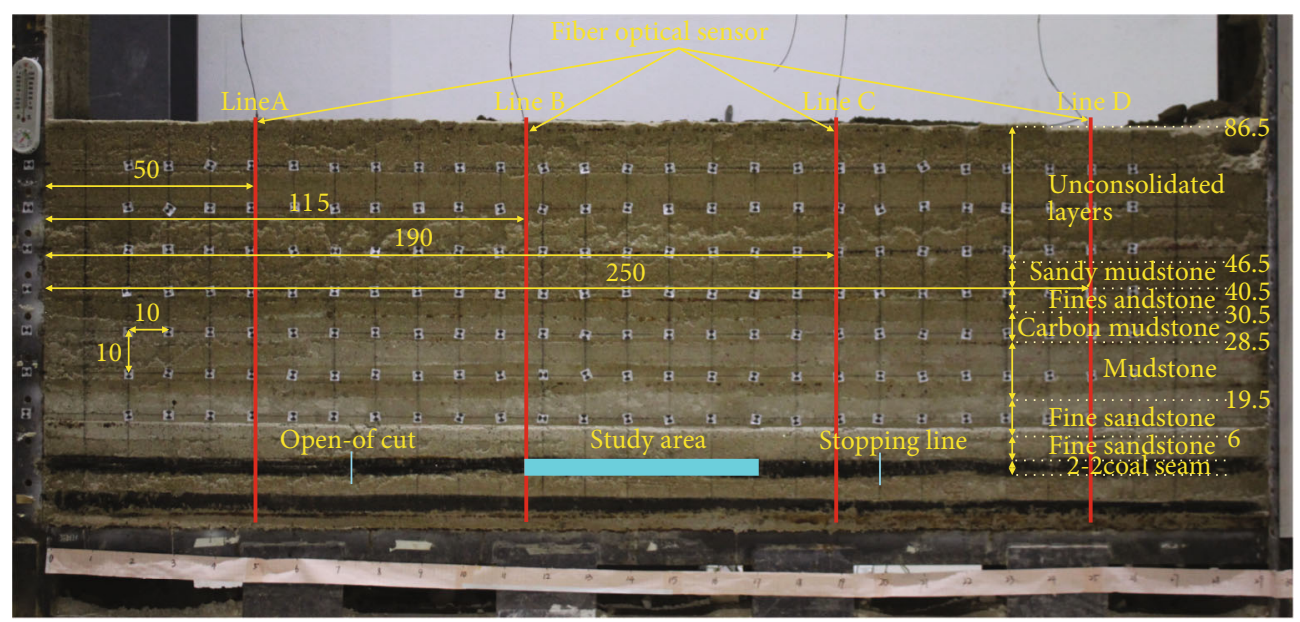

FIGURE 6: Rock distribution, fiber sensor arrangement, and research scope in model test (unit: $\mathrm{cm}$ ). 


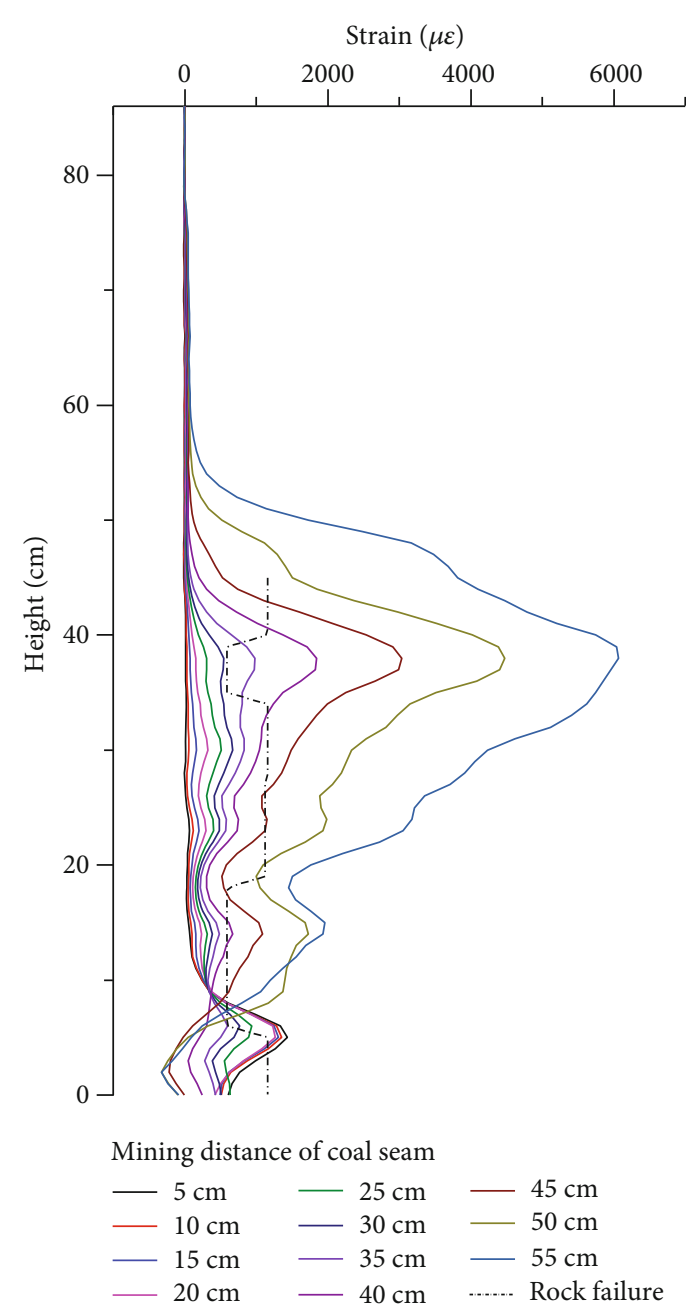

FIgURE 7: Mining-induced strain distribution measured by line B.

According to the overburden strain distribution in Figure 7, formula (2) was adopted to calculate the distributed shear stress of the fiber sensor after the working face passed the monitoring section of line $\mathrm{B}$. The calculation result is shown in Figure 8. In order to facilitate the analysis of problems, this paper chose the distributed shear stress of the fiber sensor when the working face advanced to $5 \mathrm{~cm}, 30 \mathrm{~cm}$, and $55 \mathrm{~cm}$, respectively (as shown in Figure 8). It can be seen from Figure 2 that the distribution of tensile fractures in rock strata was related to the sign changes of shear stress during coal mining. Therefore, the mean value of the shear stress of the fiber sensor was obtained to form a solid line in Figure 8 by averaging the shear stress in the same direction (indicated by a dotted line). According to the position where the sign of the shear stress changed in the solid line in Figure 8 , the overburden deformation caused by coal seam mining has the following characteristics: when the working face advanced to $5 \mathrm{~cm}$, the sign of the shear stress changed for the first time at the position $5 \mathrm{~cm}$ away from the roof of the coal seam. When the working face advanced to $30 \mathrm{~cm}$, the damaged rock mass moved towards the gob due to the pressure of the overlying strata, and the overlying rock strain gradually increased from the bottom to the top, and a num-

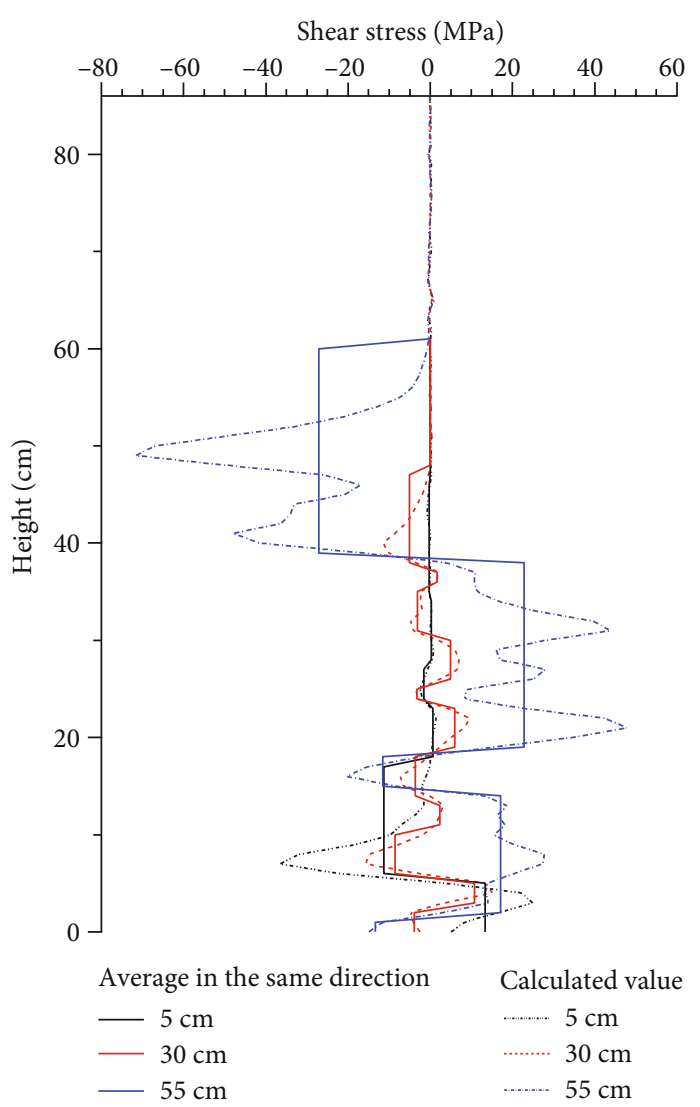

FIgURe 8: Mining-induced shear stress distribution measured by line $\mathrm{B}$.

ber of sign change points of shear stress appeared. However, according to the rock breakpoint identification formula (1), the rock at the abovementioned positions where the sign of shear stress changed has not been broken. When the working face advanced to $55 \mathrm{~cm}$, the degree of overburden disturbance intensified, and the change points of shear stress gradually concentrated at the positions $14.3 \mathrm{~cm}$ and $37.8 \mathrm{~cm}$ away from the roof of the coal seam. The magnitude of the shear stress exceeded the tensile strength of the rock. Therefore, in this test, it can be concluded that when the working face advanced to $55 \mathrm{~cm}$, the height of the water-flowing fractured zone was $37.8 \mathrm{~cm}$.

In order to grasp the characteristics of overlying stratum deformation and failure during coal seam mining, according to the monitoring requirements of photogrammetry system, noncoding points were set at $10 \mathrm{~cm}$ intervals along the horizontal and axial directions of the model, starting from the left boundary of the coal seam roof and model frame in the model test. In order to compare with the monitoring results of mining-induced overburden strain, representative images about overburden deformation after the working face passed through line B fiber sensor were selected, as shown in Figure 9. Figure 9(a) shows that when the working face advanced to $5 \mathrm{~cm}$, the rock layer $5 \mathrm{~cm}$ away from the roof of the coal seam collapsed and moved towards the gob. Figure 9(b) shows that when the working face advanced to $40 \mathrm{~cm}$, cracks appeared $14.3 \mathrm{~cm}$ and $37.8 \mathrm{~cm}$ away from the roof of the coal seam. Figure 9(c) shows that when the 


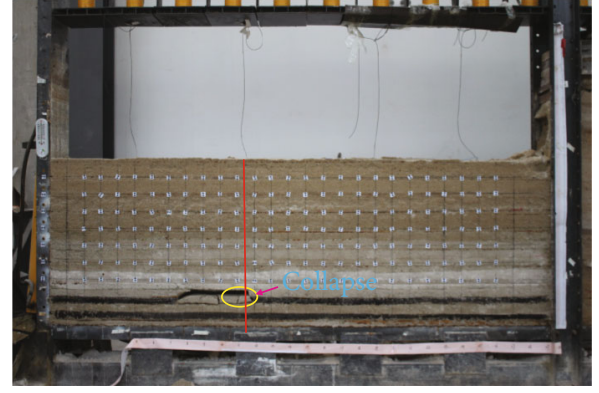

(a) Working face advanced to $5 \mathrm{~cm}$

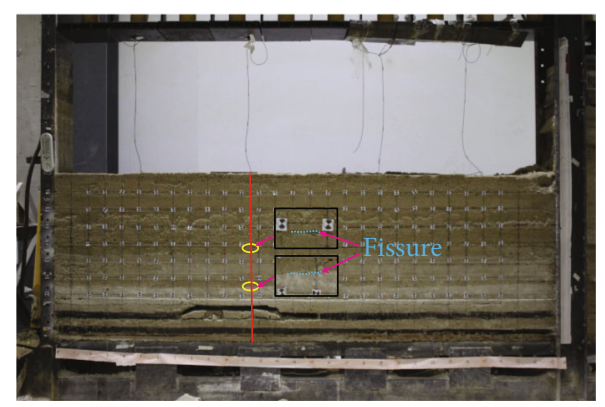

(b) Working face advanced to $40 \mathrm{~cm}$

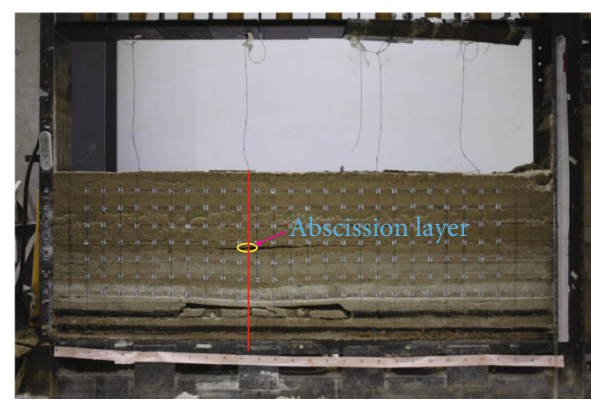

(c) Working face advanced to $60 \mathrm{~cm}$

Figure 9: Overburden deformation and failure diagram after the working face passed line B fiber sensor.

working face advanced to $60 \mathrm{~cm}$, the abscission layer was formed at $37.5 \mathrm{~cm}$ away from the roof of the coal seam, and the rock layers below the abscission layer were settled and compressed.

The height of the water-flowing fractured zone calculated by using the proposed strain-based method is basically the same with the deformation and failure results of the overlying strata in the model test.

The formula for calculating the height of the waterflowing fractured zone in building, water, railway, and main shaft roadway pillar and coal mining specification (specification in short) is shown in formula (3) [3].

$$
H=\frac{100 \sum M}{1.6 \sum M+3.6} \pm 5.6
$$

In the formula, $\sum M$ is the cumulative thickness. The cumulative mining thickness of the coal seam in this test was $4.2 \mathrm{~cm}$.

According to formula (3), the predicted height of the water-flowing fractured zone is between $35.1 \mathrm{~cm}$ and $46.3 \mathrm{~cm}$. This predicted height includes both the height of the water-flowing fractured zone calculated by the measured strain and the height of the abscission layer in the model test. It shows that the proposed method for calculating the height of water-flowing fractured zones in this paper is reliable.

\section{Discussion}

(1) The method of using the measured strain to calculate the height of the water-flowing fractured zone shows that as long as there was a crack between the upper and lower stratum layer, the sign of the shear stress changed. Due to the high resolution of the OFDR instrument, in the early stage of coal seam mining, even small strain differences in the overburden monitoring section can cause sign changes of the shear stress in many places. As the working face advanced, the crack that has appeared gradually closed, the shear stress gradually increased, and the sign changes concentrated at specific positions. Influenced by the fiber sensor's own strength, the overburden strain distribution curve was centered on the maximum deformation position of the rock mass, with the value gradually decreasing from that position to both the top layer and bottom layer. Therefore, when calculating the rock layer strength according to formula (1), a large fracture range appeared, which was not consistent with the results of the model test. The height of the water-flowing fractured zone can be accurately calculated only by combining the rock breakpoint identification formula (1) with the fracture position identification formula (2)

(2) In the study of coupling between the fiber sensor and surrounding medium, Madjdabadi et al. [21] fixed the fiber sensor to the beam body with binder and analyzed the process of coordinated deformation and strain transfer between the two. Zhang et al. [22] developed a test device for testing the interaction between the fiber sensor and soil and proposed a coupling coefficient to quantitatively describe the coupling. In the aspect of mining-induced overburden 
deformation measurement by DOFS technology, the coupling between the fiber sensor and rock mass is affected by the interaction between the two materials and rock mass structure, which needs further theoretical derivation and experimental verification to establish the shear-stress-based fracture identification criterion

(3) Using single-point sensors such as resistance strain gauge or vibrating string stress meter to monitor mining-induced overburden deformation is prone to problems including leakage detection and electromagnetic interference [23]. By applying OFDR technique, the position where overburden fracture occurs is detected accurately. However, the strain measurement range of this technology is $\pm 12000 \mu \varepsilon$. The initial deformation test in the overburden model test is relatively accurate. But when large deformation occurs, for example, an abscission layer forms, the test signal weakens until the fiber sensor breaks, and the signal cannot be tested. At present, Brillouin optical time domain reflectometry (BOTDR), Brillouin optical time domain analysis (BOTDA), Brillouin optical frequency domain analysis (BOFDA), and other testing instruments are widely used in the field of rock and soil deformation monitoring, and their strain measurement range is $\pm 15000 \mu \varepsilon$ [24]. The Brillouin back-scattering signal of the BOTDR instrument is very weak, so it is easy to miss the signal when the rock breaks and an abscission layer forms in the model test. However, this instrument has the advantage of single-end measurement, and no circuit is needed, which is suitable for field test. According to stimulated Brillouin effect, BOTDA and BOFDA instruments receive strong signals and have a high spatial resolution, which are suitable for indoor model test. But this kind of equipment requires double-ended measurement to form a test loop, and the whole monitoring section cannot be measured when the rock mass deformation is too large and the fiber sensor breaks in the field application. Therefore, in the overburden monitoring during coal seam mining, it is important to select suitable test instruments and fiber sensors according to the measurement range and develop fiber sensors suitable for measuring large deformation

\section{Conclusion}

(1) Based on the overburden strain distribution under the mining condition of coal seam, the study detected the deformation and failure state of rock mass. By combining the coordinated deformation characteristics between the fiber sensor and surrounding rock and soil mass, this paper summarized a linear relationship between the shear stress and strain gradient of the fiber sensor. By observing the position where the sign of the shear stress was changed from positive to negative, the study then detected the fracture posi- tion and proposed a method to predict the height of the water-flowing fractured zone. In addition, according to the similarity model test by using similar materials of Daliuta Coal Mine, the height of the water-flowing fractured zone was calculated to be $37.8 \mathrm{~cm}$ based on measured strain. This result is in close agreement with the actual rock failure height in the model test and the predicted height by empirical formulas' result in the specification, which indicates that the calculated result of the proposed method meets the engineering practice. Besides, this method has the characteristics of distributed measurement, high sensitivity, and good stability and has a good application prospect in measuring the height of the water-flowing fractured zone in time in the process of coal mining

(2) The OFDR measurement result shows that there was a strong linear relationship between strain and temperature. In general, if the change of temperature caused by water seepage from aquifer was small, the strain magnitude had little influence on the identification of rock fracture position. Due to the limitation of the deformation of the fiber sensor, the test signal was weakened when large deformation occurred, so it was difficult to measure the strain accurately. Therefore, it is necessary to develop a fiber sensor suitable for large deformation of overlying strata. The fracture position can be detected by the strain measured by the fiber sensor and the location where the sign of the shear stress changed, but the fracture identification based on shear stress value requires further study

\section{Data Availability}

The data used to support the findings of this study are available from the corresponding author upon request. I would like to declare on behalf of my co-authors that the work described was original research that has not been published previously and not under consideration for publication elsewhere, in whole or in part.

\section{Conflicts of Interest}

The authors declare that they have no conflicts of interest.

\section{Acknowledgments}

The work is funded by the Fundamental Research Funds for the Central Universities (2017XKQY057), and a project funded by the Priority Academic Program Development of Jiangsu Higher Education Institutions (2018).

\section{References}

[1] T. Zhang, Q. Gan, Y. Zhao et al., "Investigations into mininginduced stress-fracture-seepage field coupling effect considering the response of key stratum and composite aquifer," Rock 
Mechanics and Rock Engineering, vol. 52, no. 10, pp. 40174031, 2019.

[2] D. Zhang, G. Fan, L. Ma, and X. Wang, "Aquifer protection during longwall mining of shallow coal seams: a case study in the Shendong coalfield of China," International Journal of Coal Geology, vol. 86, no. 2-3, pp. 190-196, 2011.

[3] SAWS, State Administration of Work Safety); SACMS (State Administration of Coal Mine Safety, NEA (National Energy Administration), and SRA (State Railway Administration), Building, Water, Railway and Main Shaft Roadway Pillar and Coal Mining Specification, China Coal Industry Publishing House, Beijing, 2017.

[4] X. J. Hu, W. P. Li, D. T. Cao, and M. C. Liu, "Index of multiple factors and expected height of fully mechanized water flowing fractured zone," J Chin Coal Soc, vol. 37, pp. 613-620, 2012.

[5] V. Palchik, "Influence of physical characteristics of weak rock mass on height of caved zone over abandoned subsurface coal mines," Environmental Geology, vol. 42, no. 1, pp. 92-101, 2002.

[6] D. P. Adhikary and H. Guo, "Modelling of longwall mininginduced strata permeability change," Rock Mechanics and Rock Engineering, vol. 48, no. 1, pp. 345-359, 2015.

[7] H. Ding, "Law of overlying strata movement in large mining height working face of Bulianta coal mine," Safety in coal mines, vol. 50, pp. 179-183, 2019.

[8] D. Yang, W. Guo, and Y. Tan, "Application of magnetotelluric method to the detection of overburden failure height in shallow seam mining," Arabian Journal of Geosciences, vol. 11, no. 13, 2018.

[9] S. Liu, W. Li, and Q. Wang, "Height of the water-flowing fractured zone of the Jurassic coal seam in northwestern China," Mine Water and the Environment, vol. 37, no. 2, pp. 312321, 2018.

[10] H. Sang, D. Zhang, Y. Gao et al., "Strain distribution based geometric models for characterizing the deformation of a sliding zone," Engineering Geology, vol. 263, p. 105300, 2019.

[11] H. F. Pei, J. Teng, J. H. Yin, and R. Chen, "A review of previous studies on the applications of optical fiber sensors in geotechnical health monitoring," Measurement, vol. 58, pp. 207-214, 2014.

[12] A. Klar, I. Dromy, and R. Linker, "Monitoring tunneling induced ground displacements using distributed fiber-optic sensing," Tunnelling and Underground Space Technology, vol. 40, pp. 141-150, 2014.

[13] D. Zhang, J. Wang, P. Zhang, and B. Shi, "Internal strain monitoring for coal mining similarity model based on distributed fiber optical sensing," Measurement, vol. 97, pp. 234-241, 2017.

[14] J. Chai, Z. W. Xue, R. Guo, D. D. Zhang, Q. Yuan, and Y. Li, "Experimental study of overlying mine strata collapse and its evolution by a distributed optical fiber system," J CHINA $U$ MIN TECHNO, vol. 47, pp. 1185-1192, 2018.

[15] Y. Liu, W. Li, J. He, S. Liu, L. Cai, and G. Cheng, “Application of Brillouin optical time domain reflectometry to dynamic monitoring of overburden deformation and failure caused by underground mining," International Journal of Rock Mechanics and Mining Sciences, vol. 106, pp. 133-143, 2018.

[16] D. Tosi, E. Schena, C. Molardi, and S. Korganbayev, "Fiber optic sensors for sub-centimeter spatially resolved measurements: review and biomedical applications," Optical Fiber Technology, vol. 43, pp. 6-19, 2018.
[17] M. Froggatt and J. Moore, "High-spatial-resolution distributed strain measurement in optical fiber with Rayleigh scatter," Applied Optics, vol. 37, no. 10, pp. 1735-1740, 1998.

[18] H. Su, S. Tian, Y. Kang, W. Xie, and J. Chen, "Monitoring water seepage velocity in dikes using distributed optical fiber temperature sensors," Automation in Construction, vol. 76, pp. 71-84, 2017.

[19] C. C. Zhang, B. Shi, K. Gu et al., "Vertically distributed sensing of deformation using fiber optic sensing," Geophysical Research Letters, vol. 45, no. 21, pp. 11,732-11,741, 2018.

[20] H. M. Li, H. G. Li, G. J. Song, and K. L. Wang, "Physical and mechanical properties of the coal-bearing strata rock in Shendong coal field," Journal of China Coal Society, vol. 41, no. 11, pp. 2661-2671, 2016.

[21] B. Madjdabadi, B. Valley, M. B. Dusseault, and P. K. Kaiser, "Experimental evaluation of a distributed Brillouin sensing system for measuring extensional and shear deformation in rock," Measurement, vol. 77, pp. 54-66, 2016.

[22] C. C. Zhang, H.-H. Zhu, and B. Shi, "Role of the interface between distributed fibre optic strain sensor and soil in ground deformation measurement," Scientific Reports, vol. 6, no. 1, 2016.

[23] S. J. Chen, H. Zhou, W. J. Guo, H. L. Wang, and X. Z. Sun, "Study on long-term stress and deformation characteristics of strip pillar," Journal of Mining and Safety Engineering, vol. 29, no. 3, pp. 376-380, 2012.

[24] J. Shen, T. Li, H. Zhu, C. Yang, and K. Zhang, "Sensing properties of fused silica single-mode optical fibers based on PPPBOTDA in high-temperature fields," Sensors, vol. 19, no. 22, p. 5021, 2019. 